\title{
Adsorption of volatile organic compounds and microwave regeneration on self-prepared high- surface-area beaded activated carbon
}

\author{
Shih-Ying Hsiao \\ National Taiwan University \\ Shu-Wen You \\ National Taiwan University
}

Can Wang

Tianjin University

Ji-Guang Deng

Beijing University of Technology

Hsing-Cheng Hsi ( $\nabla$ hchsi@ntu.edu.tw )

National Taiwan University https://orcid.org/0000-0001-5558-2077

\section{Research Article}

Keywords: volatile organic compounds, toluene, methyl ethyl ketone, beaded activated carbon, microwave regeneration

Posted Date: October 5th, 2021

DOl: https://doi.org/10.21203/rs.3.rs-948405/v1

License: (9) (1) This work is licensed under a Creative Commons Attribution 4.0 International License. Read Full License

Version of Record: A version of this preprint was published at Aerosol and Air Quality Research on January 1st, 2022. See the published version at https://doi.org/10.4209/aaqr.220010. 
4 Shih-Ying Hsiao ${ }^{1}$, Shu-Wen You ${ }^{2}$, Can Wang ${ }^{2,3}$, Ji-Guan Deng ${ }^{4}$, and Hsing-Cheng

$6{ }^{1}$ Graduate Institute of Environmental Engineering, National Taiwan University, No. 1,

$8 \quad{ }^{2}$ School of Environmental Science and Engineering, Tianjin University, Tianjin 
* Correspondence: hchsi@ntu.edu.tw

15 
Self-prepared beaded activated carbons (SBAC) were derived from carbonized phenolic formaldehyde (PF) resins through an optimal activation procedure $\left(900{ }^{\circ} \mathrm{C}\right.$ for

$194 \mathrm{~h}$ ) using $\mathrm{CO}_{2}$. A commercial BAC (termed KBAC) was adopted to compare with

20 SBAC over physicochemical properties, adsorption performance against methyl ethyl

21 ketone (MEK) and toluene (TOL), and the regenerability using microwave irradiation.

22 Langmuir, Freundlich, and Dubinin-Radushkevich (D-R) isotherm models showed

23 good fitting results to explain the adsorption equilibrium. The isosteric heat of

24 adsorption was calculated using the Clausius-Clapeyron equation; the parameters

25 obtained from the D-R isotherm indicate that the interactions between adsorbate and

26 adsorbent were mainly due to physisorption. Microwave heating was applied to the

27 regeneration of saturated adsorbents to examine the effect of irradiation power and

28 heating time on the desorption behavior of adsorbate. Within 12 min of microwave

29 irradiation, excellent desorption efficiencies based on gravimetric method were shown,

30 reaching $110.7 \pm 14.4,104.4 \pm 2.6,90.2 \pm 2.3$, and $85.5 \pm 5.7 \%$ for MEK-SBAC, MEK-

31 KBAC, TOL-SBAC, and TOL-KBAC samples, respectively. After an 8-cycle of 32 adsorption/regeneration, the adsorption capacity for SBAC was significantly decreased 
33 when loaded with TOL, whereas it was more significant than the virgin sample as

34 loaded with MEK. In contrast, KBAC was able to sustain the adsorption capacity after

35 an 8-cycle of regeneration, proving its stability throughout the microwave heating.

36 Kinetic models were further employed to illustrate the desorption of the adsorbates

37 from BAC samples, showing that intraparticle diffusion in SBAC and KBAC was the

38 rate-limiting step during microwave heating. The core kinetic parameters obtained

39 could provide insights for lab-scale adsorbent beds or practical engineering scale design.

40 In conclusion, this study demonstrates the excellent adsorption performance of SBAC

41 and the feasibility of microwave regeneration of BACs.

42 Keywords: volatile organic compounds, toluene, methyl ethyl ketone, beaded activated

43 carbon, microwave regeneration

\section{Introduction}

45

In the past decades, volatile organic compounds (VOCs) emitted from

46 anthropogenic activities have become one group of the significant pollutants harmful to human health and the environment. In addition to the adverse effects, VOCs are also the precursors to the photochemical smog, the near-surface ozone and are responsible 
51 Up to now, numerous abatement techniques have been proposed and adopted to reduce the VOCs emission from stationary sources, such as thermal/catalytic oxidation,

53 biological conversion, membrane separation, absorption, condensation, and adsorption

54 [2-4]. Among the removal technologies, the adsorption process based on a suitable

55 adsorbent is a compelling method due to its cost-effectiveness and simplicity, and the

56 potential in recovering high-priced VOCs via thermal regeneration followed by

57 condensation $[5,6]$.

58 One of the widely used porous materials is activated carbon (AC). AC has garnered

59 considerable attention for its remarkable properties: its predominantly hydrophobicity,

60 high thermal stability, low cost, chemical inertness, and low energy consumption for

61 regeneration [7]. Furthermore, because of the non- or weak polar surface of AC,

62 physisorption is typically the dominant adsorption mechanism for VOCs. The overall

63 adsorption performance of AC is mainly attributed to its high specific surface area. It

64 is also dependent on the size, molecular weight, polarizability, concentration, and

65 complexity of the adsorbate $[2,8,9]$.

66 To enhance the adsorption performance over specific compounds, ACs are usually 
subjected to chemical activation using acid/base reagents or physical modification under oxidizing gases $\left(\mathrm{CO}_{2}\right.$, steam, or air $)$ at high temperatures $\left(700-1000{ }^{\circ} \mathrm{C}\right)$ to adjust surface areas and chemical functional groups on the surface [10].

71 beaded forms have been developed to adapt to different scenarios [11]. Beaded

72 activated carbon (BAC) is employed in a wide range of industrial applications due to

73 its excellent properties such as high mechanical strength, porous structure, large surface

74 area, high micropore volume, good fluidity, and decent adsorption performance [12,

75 13]. A variety of polymeric-based precursors, including phenolic, sulfonated

76 polystyrene, divinylbenzene, and phenol-formaldehyde (PF) have been adopted for

77 BAC manufacturing, and BAC with high mechanical strength, high carbon content, and

78 low ash content could be obtained. However, it is challenging to produce BAC with a

79 perfect sphere and smooth surface without cracks since the types of precursors and

80 adjustment of parameters in stabilization, carbonization, and physical/chemical

81 activation have huge impacts on the resultant products $[14,15]$. Our previous studies

82 served as compelling illustrations of this $[16,17]$; to deal with the waste bioresources,

83 self-prepared BAC (SBAC) was derived from the mixture of PF-based resin, formalin, 
84 and waste bamboo tar under various experimental conditions. Based on the scanning

85 electron microscope (SEM) micrographs, the non-uniform surface and cracking

86 phenomenon of SBAC became even severe as activation temperature and time

87 increased compared with a commercial product termed KBAC (where $\mathrm{K}$ stands for

88 Kureha CORP.). Although the optimal synthesis conditions were acquired according to

89 a series of comprehensive investigations on activation temperature $(800,850$, and 900

$\left.90{ }^{\circ} \mathrm{C}\right)$ and activation time $(2,3$, and $4 \mathrm{~h})$ during the fabrication of SBACs, the overall

91 adsorption performance for some widely used VOCs and the total surface area were

92 still needed to be improved. Furthermore, our previous studies lacked an in-depth

93 exploration of the effect on the adsorption capacity or regeneration efficiency of

94 adsorbents via cyclic adsorption and microwave regeneration procedures.

95 Therefore, in continuation to our earlier study (Chen et al. [17]), the present research

96 focuses on (i) establishing equilibria and kinetic mechanisms of BACs, including self-

97 prepared high-surface-area and commercial samples, toward methyl ethyl ketone

98 (MEK) and toluene (TOL), which are the two major species emitted from the

99 polyurethane (PU) industry in Taiwan [18, 19]; (ii) exploring the effect of microwave

100 power output and irradiation time during the regeneration of exhausted BACs; and 
101 finally, (iii) identifying the effect of heel buildup during cyclic adsorption/regeneration

102 of MEK and TOL, and evaluating the feasibility of this technology.

103 2. Materials and methods

104 2.1. Adsorbent preparation

105 The synthesis of SBAC could be broken down into two stages, including 106 carbonization under an inert atmosphere and subsequent activation using $\mathrm{CO}_{2}$ 107 (99.999\%). All the experiments were carried out in a vertical quartz reactor (30-mm 108 i.d.), heated by a conventional temperature-programmed heating furnace (DENGYNG, 109 model D-35). First, commercial PF resin spheres as the raw material of SBAC, were 110 sieved to a selected size (around $150 \mu \mathrm{m}$ ) and placed in the center of the vertical quartz

111 reactor. Then, carbonization took place under $500{ }^{\circ} \mathrm{C}$ for $1 \mathrm{~h}$ in the $\mathrm{N}_{2}$ atmosphere 112 (99.999\%) to remove volatile contents in the material and to reform the carbon structure.

113 The carbonized PF resin spheres were then physically activated. The temperature

114 increased from room temperature to $900{ }^{\circ} \mathrm{C}$ in the $\mathrm{N}_{2}$ atmosphere at the heating rate of

$11510{ }^{\circ} \mathrm{C} \min ^{-1}$; the gas was then switched to $\mathrm{CO}_{2}$ at $900{ }^{\circ} \mathrm{C}$ and held for $4 \mathrm{~h}$, the gas flow 116 rate was controlled at $0.1 \mathrm{~L} \mathrm{~min}^{-1}$ by a rotameter.

117 The commercial KBAC used for comparison in this study was heated in an oven at 105 
$118{ }^{\circ} \mathrm{C}$ over $24 \mathrm{~h}$ to remove adsorbed moisture. Afterward, all samples were stored in a

119 desiccator before use.

\subsection{Physicochemical characterization of materials}

\subsubsection{Morphology and pore structure}

122 The surface morphology of virgin and regenerated BACs was analyzed by a field-

123 emission SEM (Hitachi, model S-4800) and a transmission electron microscope (TEM;

124 Hitachi, model $\mathrm{H}-7100$ ). The $\mathrm{N}_{2}$ adsorption was carried out at $77 \mathrm{~K}$ (Micromeritics,

125 model ASAP 2420) to examine the pore structure of BACs. All samples were degassed

126 at $350{ }^{\circ} \mathrm{C}$ for $15 \mathrm{~h}$ to remove moisture and impurities before the measurement. Specific

127 surface area $\left(S_{\text {total }}\right)$ was calculated using the Brunauer-Emmett-Teller (BET) equation.

128 Micropore surface area $\left(S_{\text {micro }}\right)$ and micropore volume $\left(V_{\text {micro }}\right)$ were obtained from the

129 t-plot analysis by applying the Harkins and Jura thickness curve, $t=[13.99 /(0.034-$

$\left.\left.130 \log \left(\mathrm{P} / \mathrm{P}_{0}\right)\right)\right]^{0.5}$. The range of relative pressures used to determine $S_{\text {micro }}$ and $V_{\text {micro }}$ was

131 based on a statistical thickness t-value of $0.45-0.80 \mathrm{~nm}$. Total pore volume $\left(V_{\text {total }}\right)$ was

132 determined by the Barrett-Joyner-Halenda (BJH) method and recorded at $\mathrm{P} / \mathrm{P}_{0}=0.994$.

133 The pore size distribution (PSD) of the mesopore and macropore range was also

134 evaluated by the BJH method. Nonlocal density functional theory (NLDFT) was used 
135 to assess the PSD of the micropore size range.

\subsubsection{Elemental analysis (EA)}

137 The elemental analysis for $\mathrm{C}, \mathrm{H}, \mathrm{O}, \mathrm{N}$, and $\mathrm{S}$ of $\mathrm{BACs}$ was performed on an

138 elemental analyzer (Elementar, model vario EL cube). The samples were completely

139 burned and converted into a gas mixture, and the mass fraction of each element was

140 determined by a thermal conductivity detector (TCD) downstream.

141 2.2.3. Thermogravimetric analysis (TGA)

142 The pyrolysis tests were performed in a thermogravimetric analyzer (SHIMADZU,

143 model TGA-51). The sample was put into a platinum crucible, and the experiments

144 were carried out at atmospheric pressure using $\mathrm{N}_{2}$ as the purging gas (flow rate $=50 \mathrm{ml}$

$145 \mathrm{~min}^{-1}$ ) to desorb the species at heating rates of 5,10 , and $20{ }^{\circ} \mathrm{C} \mathrm{min}-1$. The weight loss

146 of the sample and the temperature were recorded continuously within a temperature

147 range of 25 to $600{ }^{\circ} \mathrm{C}$.

148 2.3. Adsorption and regeneration processes

149 2.3.1. VOCs adsorption measurements and isotherm construction

150 The schematic diagram of the adsorption testing system comprises a VOCs vapor

151 generating system, a temperature-controlled adsorption bed, a total hydrocarbon (THC)

152 analyzer, and a data acquisition system (DAQ) is depicted in Figure 1. The selected 
153 solvents (MEK and TOL) were injected into a heating furnace (designed by Fortelice

154 International Co., Ltd.) at a constant rate with a gastight syringe (Hamilton Company)

155 and a syringe pump (New Era Pump Systems Inc., model NE 1000). The temperature

156 of the heating furnace was monitored by a K-type thermocouple and set well above the

157 boiling point of both solvents $\left(79.6{ }^{\circ} \mathrm{C}\right.$ and $110.6{ }^{\circ} \mathrm{C}$ for MEK and TOL, respectively)

158 to ensure the solvents vaporized immediately and mixed with the inert carrier gas $\left(\mathrm{N}_{2}\right.$,

159 purity $=99.999 \%$ ). The injection rates of solvents were adjusted based on the ideal gas

160 law to generate desired VOCs concentrations in the gas stream.

161 The online THC detecting system was a flame ionization detector (FID) (Ratfisch

162 Analysensysteme $\mathrm{GmbH}$, model RS53-T) continuously measuring the outlet

163 concentrations of the adsorption bed. The DAQ system consisted of a Labview software

164 (National Instruments) and a data logger (National Instruments, model USB-6000)

165 acquired one data point per second.

166 The adsorption experiments were carried out in a Pyrex glass tube $(40 \mathrm{~cm}$ in length

167 and $1 \mathrm{~cm}$ in diameter), pre-treated BACs of 20-50 mg were measured and placed in the

168 center of the tube and supported by a sintered glass filter. The adsorption bed was

169 heated by heating tape (Omega). The temperature was well measured and controlled by 
170 a proportional integral derivative (PID) controller with a K-type thermocouple inserting

171 in the adsorption bed; the operating temperature was set at 30,40 , and $50{ }^{\circ} \mathrm{C}$. The

172 adsorption of VOCs onto the tube and glass filter was assumed negligible during the

173 test.

174 For the adsorption isotherm construction, the concentration of VOCs ranged from

1750.0007 to $0.16 \mathrm{P} / \mathrm{P}_{0}$ and 0.002 to $0.21 \mathrm{P} / \mathrm{P}_{0}$ for $\mathrm{MEK}$ and TOL, respectively. For the

176 dynamic analysis of the adsorption bed, the operating temperature and the inlet

177 concentrations of MEK or TOL were controlled at $500 \mathrm{ppmv}$ and $40{ }^{\circ} \mathrm{C}$. Smooth

178 breakthrough curves were generated, and data were stored for subsequent analysis. The

179 adsorption tests were conducted in triplicate for all experimental concentrations. The

180 total gas flow rate was controlled at 1.6 SLPM by mass flow controllers (Brooks®

$1815850 \mathrm{E})$.

182 Two methods were employed to calculate the saturated adsorption capacity. For the

183 gravimetric method, the adsorption capacity was obtained from the weight difference

184 of the BACs before and after the adsorption, which could be calculated by the following

185 equation:

$$
\text { Adsorption capacity }(\%)=\frac{W_{A A}-W_{B A}}{W_{B A}} \times 100 \%
$$


where $W_{A A}$ is the weight of the adsorbent after adsorption and $W_{B A}$ is the weight of the

188 adsorbent before adsorption.

189

The other approach to calculate the saturated adsorption capacity is by integrating

190 the areas above the breakthrough curves. Therefore, the saturated adsorption capacity

191 was calculated as follows:

$$
\text { Adsorption capacity }(\%)=\frac{\int\left(C_{i n}-C_{\text {outlet }, i}\right) \times V_{a d} \times \rho_{G}}{W_{B A}} \times 100 \%
$$

193 where $C_{\text {in }}$ is the inlet concentration $\left(\mathrm{ppm}_{\mathrm{v}}\right), C_{\text {outlet, } i}$ is the VOCs outlet concentration

$194\left(\mathrm{ppm}_{\mathrm{v}}\right)$ during the period of adsorption at i interval of time, and the time interval was

195 set as one second. $V_{a d}$ is total gas volume $\left(\mathrm{m}^{3}\right), \rho_{G}$ is the density of the organic vapor,

196 and $W_{B A}$ is the weight of the adsorbent before adsorption.

197 2.3.2. Microwave regeneration

Figure S1 shows the setup of the microwave regeneration system. All adsorbents

were exposed to MEK or TOL under an inlet concentration of $500 \mathrm{ppm}_{\mathrm{v}}$ at $40{ }^{\circ} \mathrm{C}$ until

201 placed in a quartz boat within a $1.5 \mathrm{~L}$ quartz reactor and heated in a microwave muffle

202 furnace (Milestone, model Pyro 260) operated at $2.45 \mathrm{GHz}$. The setting power ranged

203 from 400 to $1000 \mathrm{~W}$, and the heating time was 4 to $12 \mathrm{~min}$. To create an oxygen-free 
atmosphere, the reactor was purged by $\mathrm{N}_{2}($ purity $=99.999 \%)$ with a flow rate of $1.5 \mathrm{~L}$ $\min ^{-1}$ for more than $5 \mathrm{~min}$. The temperature profile of the adsorption bed was obtained using a K-type thermocouple with a ceramic sheath during microwave heating. The desorbed adsorbates were directed to the FID for concentrations measurement. microwave regeneration, a portable gas analyzer (HORIBA, model PG-350) was used to measure $\mathrm{NO}, \mathrm{SO}_{2}, \mathrm{CO}$, and $\mathrm{CO}_{2}$ in the exhaust gas stream. The measurement range

211 was set at 0 to $200 \mathrm{ppm}$ for $\mathrm{SO}_{2}$ and $\mathrm{CO}, 0$ to $25 \mathrm{ppm}$ for $\mathrm{NO}_{\mathrm{x}}$, and 0 to $10 \%(\mathrm{v} / \mathrm{v})$ for

$212 \mathrm{CO}_{2}$. The data of the outlet gas concentrations were recorded during the time interval

213 of one second.

214 The desorption efficiency is defined as:

$$
\text { Desorption efficiency }(\%)=\frac{W_{B R}-W_{A R}}{W_{B R} \times q_{500} p p m} \times 100 \%
$$

216 where $W_{B R}$ and $W_{A R}$ are the weight of the adsorbent before and after regeneration,

217 respectively, and $q_{500} \mathrm{ppm}$ is the adsorption capacity at $500 \mathrm{ppm}_{\mathrm{v}}$ and $40{ }^{\circ} \mathrm{C}$.

\subsubsection{Cyclic adsorption/regeneration test}

220 calculated from integration and gravimetric methods. To ensure the accuracy and 
221 consistency of the data, the adsorption capacity after each cycle was calculated by the

222 gravimetric method in the cyclic test. The regeneration performance was evaluated by

223 regeneration efficiency, which was calculated by Eq. (4):

224

$$
\text { Regeneration efficiency }(\%)=\frac{q_{r}}{q_{0}} \times 100 \%
$$

225 where $q_{0}$ is the quantity of adsorbate adsorbed per unit weight of adsorbent and $q_{r}$ is the

226 quantity of adsorbate adsorbed per unit weight of regenerated adsorbent.

\section{2.3.4. Desorption kinetics analysis}

To better describe the interaction between the adsorbate and the adsorbent, the

pseudo-first-order model and intraparticle diffusion model were used in this study to

obtain the core kinetics coefficients. The kinetics data is necessary and advantageous

231 for designing an adsorption bed appropriately.

232

Three consecutive steps of a species physisorbed onto a porous adsorbent are (i)

233

transport of the adsorbate from gas film to the external surface of the adsorbent

234 (external diffusion), (ii) transport of the adsorbate within the pores of the adsorbent

235 (intraparticle diffusion), and (iii) adsorption of the adsorbate on the exterior surface of

236 the adsorbent (surface diffusion). Generally, it is accepted that surface diffusion is very

237 rapid [20], and intraparticle diffusion is often considered the rate-controlling step in an 
238 adsorption process [21]. For a desorption process, the pathways of reactions are

239 opposite to the adsorption process.

240 (1) Pseudo-first-order (PFO) model

241 If external diffusion was the rate-controlling step, the rate of adsorption could be

242 described by the PFO model [22]:

243

$$
\ln \left(1-\frac{q_{t}}{q_{e}}\right)=-k_{1} t
$$

244 where $q_{e}$ and $q_{t}$ are the amount of adsorbate adsorbed by the sorbent at equilibrium

245 and time $t$, respectively, and $k_{1}$ is the PFO adsorption rate constant.

246 (2) Intraparticle diffusion model (IPD)

model could be described as:

250

$$
q_{t}=k_{p} t^{1 / 2}+I
$$

251 where $q_{t}$ is the adsorption capacity at time $t, k_{p}$ is the IPD rate constant, and $I$ is the

252 intercept reflecting the extent of the boundary layer thickness.

\section{Results and discussion}

\subsection{Adsorbent characterization}


The morphologies of SBAC and KBAC were examined by SEM (Figure $2 \mathrm{a}$ and $\mathrm{b}$ ).

257 Both of their appearances were in round shape, which is suitable for fixed-bed packing

258 and fluidity operation. Additionally, the surface of SBAC was smoother than KBAC,

259 indicating the mechanical strength might be higher in SBAC. In addition, well-

260 developed inner structures were found in SBAC while there were only scattered

261 fragments on the surface of KBAC.

262 The TEM micrographs of SBAC (Figure $2 \mathrm{~g}$ ) reveal a more detailed understanding

263 of the inner structure, suggesting that the 3-D pores were randomly combined and

264 constructed amorphous nanostructures.

265 The effect of microwave regeneration on BACs was also evaluated via SEM

266 analysis (Figure 2c-f). BACs saturated with MEK and TOL at $500 \mathrm{ppmv}$ and $40{ }^{\circ} \mathrm{C}$

267 (termed MEK-KBAC, TOL-KBAC, MEK-SBAC, and TOL-SBAC) were subjected to

268 microwave regeneration, and the samples regenerated at $800 \mathrm{~W}$ for 8 min were chosen

269 for SEM analysis. According to the results, there were no significant differences in the

270 outward appearance between the virgin and regenerated KBAC. However, the pore

271 structure of the regenerated MEK-SBAC (Figure 2c) experienced changes due to the 
272 polarity between the adsorbate and SBAC or the non-uniform heating during the

273 microwave regeneration.

274 3.1.2. EA results and pore structures of BACs

275 Table 1 shows the EA results for both virgin and post-regenerated samples

276 (regenerated at $800 \mathrm{~W}$ for $8 \mathrm{~min}$ ). A similar proportion of hydrogen and oxygen in

277 virgin SBAC and $\mathrm{KBAC}$ suggested possibly similar polarities on their surfaces. It is

278 said that oxygen-containing groups tend to exchange electrons with the p-orbital

279 electrons of aromatic compounds such as TOL to form chemical adsorption. As a result,

280 the lower oxygen contents of TOL-BACs after microwave regeneration might be

281 caused by chemisorbed TOL remained on the adsorbents since the regeneration

282 temperature was not high enough to remove the adsorbed TOL [24].

283 The $\mathrm{N}_{2}$ adsorption-desorption isotherm conducted at $77 \mathrm{~K}$ and PSD of BACs are

284 shown in Figure 3. Both SBAC and KBAC followed the type I adsorption isotherm

285 classified by the latest version of the International Union of Pure and Applied

286 Chemistry (IUPAC) definition, which was typically indicative of the microporous

287 character of a porous material. Furthermore, the PSD results examined by NLDFT and

288 BJH methods had revealed that several sharp peaks within $0.5-2.0 \mathrm{~nm}$, indicating that 
289 both SBAC and KBAC were microporous with wider micropores and narrower

290 mesopores.

291 The overall physical properties of virgin and regenerated BACs are also displayed

292 in Table 1. SBAC synthesized under the optimal experimental conditions (activated at

$293900{ }^{\circ} \mathrm{C}$ for $4 \mathrm{~h}$ ) according to our previous study (Chen et al. [17]) using PF resins had

294 shown tremendous improvement in surface area, possessing the largest $S_{\text {total }}$ of $2114 \mathrm{~m}^{2}$

$295 \mathrm{~g}^{-1}$ and $V_{\text {total }}$ of $1.361 \mathrm{~cm}^{3} \mathrm{~g}^{-1}$ while KBAC used in this study showed a $S_{\text {total }}$ of $1210 \mathrm{~m}^{2}$

$296 \mathrm{~g}^{-1}$ and $V_{\text {total }}$ of $0.602 \mathrm{~cm}^{3} \mathrm{~g}^{-1}$, which were lower than that of SBAC. The collapse of

297 micropore structures might cause the decline in the $S_{\text {total }}$ and $V_{\text {total }}$ of the regenerated

298 BAC samples during the microwave regeneration or the pore blockage by the molecules

299 of MEK or TOL that were unable to desorb.

300

\subsubsection{TGA results}

301

Thermogravimetric analysis (TGA) was employed to understand the desorption

302 pattern of the adsorbate in the adsorbents and could obtain an insight into the optimal

303 microwave regeneration temperature. The virgin BACs were subjected to TGA analysis

304 and showed only slight weight loss during the TGA progress at around $90{ }^{\circ} \mathrm{C}$ (Figure

305 4a). It could be attributed to moisture desorption, usually observed in activated carbon 
previously exposed to ambient air [25].

BACs loaded with MEK and TOL were thermally desorbed at heating rates of 5,

30810 , and $20{ }^{\circ} \mathrm{C} \mathrm{min}^{-1}$ from room temperature to $600{ }^{\circ} \mathrm{C}$. For all samples, we found that

309 the desorption of compounds occurred at temperatures between 100 and $400{ }^{\circ} \mathrm{C}$, and

310 the sorbents could be completely desorbed within $400{ }^{\circ} \mathrm{C}$.

311 On the other hand, the weight loss of saturated BACs became slower at rapid

312 heating rates, resulting from the heel buildup within the adsorbents. Niknaddaf et al.

313 [26] pointed out that the increase of heating rate from 5 to $100{ }^{\circ} \mathrm{C} \min ^{-1}$ led to $8-52 \%$

314 of capacity loss as well as $4.6-10.5 \%$ of heel buildup for activated carbon fiber cloth

315 (ACFC) in five consecutive adsorption/regeneration operations, respectively.

316 The differential thermal gravimetry (DTG) curve is a plot of the adsorbate's

317 desorption rate as a function of the sample temperature. As a whole, the DTG data were

318 used to evaluate the activation energy $(E d)$ of different organic materials. Since the

319 desorption peak temperature is related to the adsorption strength, a more robust

320 interaction gives rise to a higher peak temperature. The desorption peak under $100{ }^{\circ} \mathrm{C}$

321 is attributed to water desorption [25]. Assuming that the desorption followed first-order

322 kinetics and the heating rate is constant (i.e., $T=T_{0}+\beta t$ ), based on the Arrhenius 
323

324

equation, the $E d$ for desorption could be calculated by the following equation [27]:

$$
\ln \left(\frac{\beta}{R T_{M}^{2}}\right)=-\frac{E_{d}}{R T_{M}}+C
$$

325

where $T_{M}$ is the peak desorption temperature, $\beta$ is the heating rate, $E_{d}$ is the desorption

326 activation energy, $R$ is the universal gas constant, and $C$ is the constant that depends on

327 the desorption kinetics.

328

The DTG curves for SBAC and KBAC are shown in the Supplementary Materials

329 (see Figure S2-5), and the calculated $E_{d}$ (tabulated in Table S1) for MEK and TOL in

330 this study was similar to or slightly higher than the heat of vaporization for MEK and

331 TOL (31.2 and $32.8 \mathrm{KJ}$ mole $^{-1}$ at boiling point for MEK and TOL, respectively), which

332 could be characterized as physical adsorption onto both SBAC and KBAC [25]. temperatures and inlet concentrations. The data for VOCs adsorption was fitted by three isotherms, namely Langmuir, Freundlich, and Dubinin-Radushkevich (D-R) isotherms.

\subsection{Adsorption and desorption performance}

\subsubsection{Adsorption isotherm construction}

Adsorption isotherm provides essential information to predict the adsorption performance and the maximum adsorption capacity of BACs under various adsorption

Detailed description pertaining to these isotherms is presented in Supporting 
340 Information (SI). The inlet concentrations of the VOCs were set in the range within 100

341 to $20,000 \mathrm{ppm}_{\mathrm{v}}$ for MEK and 100 to $10,000 \mathrm{ppm}_{\mathrm{v}}$ for TOL, respectively, covering the

342 whole range of concentration that could be detected by the FID.

343 The fitting results of the experimental data based on the integration and gravimetric

344 methods are tabulated in Table $\mathrm{S} 2-4$. The $\mathrm{R}^{2}$ for the gravimetric method was generally

345 higher than that for the integration method with minimum values of $0.894,0.948$, and

3460.948 for Langmuir, Freundlich, and D-R isotherms, respectively. The plots of the

347 experimental and Langmuir isotherm modeled data are also presented in Figure 5.

348 Graphically, Langmuir isotherm is characterized by a plateau corresponding to a

349 saturated adsorption capacity $\left(q_{s}\right)$. The $q_{s}$ calculated by the integration method seemed

350 much higher than that obtained by the gravimetric method. Although the $q_{s}$ gained from

351 both two methods were similar at the lower concentration range, the $q_{s}$ showed a

352 significant deviation as the concentration increased. This could result from the response

353 time of the THC detector that amplified the deviation of the breakthrough curve. As a

354 result, the $q_{s}$ estimated by the gravimetric method appeared to be more accurate.

355 According to the gravimetric results, the $q_{s}$ of SBAC is consistently higher than that of

356 KBAC, which could be stemmed from the higher surface area and larger pore volume 
Figure 6 shows the plots of Freundlich isotherm fitting results. Judging by the $\mathrm{R}^{2}$

361 function of the strength of adsorption or surface heterogeneity. The larger the value of

$362 n$, the stronger the adsorption affinity, indicating more heterogeneous adsorption [28].

363 As shown in Table S3, in most cases, $K_{F}$ increased and $n$ decreased with increasing

364 operating temperature. The value of $n$ was more significant than 1 for all scenarios,

365 revealing the heterogeneity of the carbon surface. Owing to its lack of a finite limit

366 under high pressure, the Freundlich isotherm cannot fit broad concentration ranges. experimental and the D-R isotherm modeled data are presented in Figure 7. The D-R model has been proven to be suitable for the description of adsorption in activated were mostly over 0.96 . Generally, $W_{0}$ is the maximum capacity available for adsorbate, 
374 analysis shown previously (Table 1), SBACs developed higher proportions of

375 micropores compared to KBAC. However, the calculated $W_{0}$ seemed inconsistent with

376 those obtained from $\mathrm{N}_{2}$ adsorption. The main reason was the difference in the kinetic

377 diameters of the probing molecules $\left(\mathrm{N}_{2}: 4.02 \AA\right.$, MEK: $5.25 \AA$, and TOL: $5.85 \AA$ ),

378 contributing to the difference in $W_{0}$.

379 The characteristic energy, $E$ ( or $E_{0} \beta$ ), is a parameter concerning pore size, surface

380 chemistry, and adsorbate structure [29]. In this study, the characteristic energies of

381 adsorption of MEK and TOL onto SBAC were about 8 to $10 \mathrm{~kJ} \mathrm{~mol}^{-1}$, suggesting that

382 physical adsorption predominates in the adsorption process. On the other hand,

383 compared with SBAC, the free energy of MEK and TOL adsorbed onto KBAC was

384 higher (10-18 $\left.\mathrm{kJ} \mathrm{mol}^{-1}\right)$ but still characterized as physical adsorption.

385 Once the characteristic energy is gained from the adsorption isotherm data, the

386 characteristic pore dimensions of a porous carbon can also be estimated. There is an

387 inverse proportionality between $E$ and the slit-pore half-width $\left(x_{0}\right)$, which takes the

388 following form:

$$
x_{0}=k / E_{0}
$$

390 For most industrial activated carbons whose $E$ is less than $22 \mathrm{~kJ} \mathrm{~mol}^{-1}$, the 
391 corresponding values of $k$ are almost constant and can be set approximately to $13 \mathrm{~kJ}$

$392 \mathrm{~nm} \mathrm{~mol}^{-1}[30]$.

393 As observed in Table S4, the values of $x_{0}$ for SBACs are larger than those for

394 KBACs. Most results showed an acceptable agreement using MEK or TOL as a probing

395 molecule. In contrast, some deviated results could be attributed to data errors or

396 narrower pore sizes in adsorbents, which hindered diffusion of larger molecules. It

397 should be noted that the VOCs considered in this study is relatively small, and the

398 adsorption capacity trends may differ from those established here for larger adsorbates

399 (e.g. polychlorinated dibenzo-p-dioxins and -furans) [31].

400 3.2.2. Isosteric heat of adsorption

401 The isosteric heats can be calculated using the D-R parameters and Clausius-

402 Clapeyron equation [9]. However, as mentioned in previous sections, the deviation of

403 adsorption capacities using different calculation methods was significant. Therefore, to

404 maintain accuracy and consistency, the D-R isotherm data used in calculating $\Delta H s$ were

405 based on gravimetric methods. The dependences on adsorbate, temperature, and surface

406 loading in calculating $\Delta H s$ are illustrated in Figure 8.

407 A rule of thumb in adsorption is that for adsorption heat $<80 \mathrm{~kJ}$ mole ${ }^{-1}$, the 
408 adsorption process is characterized as physisorption [32]. As shown in Figure 8, the

$409 \Delta H s$ ranges from 35 to $60 \mathrm{~kJ} \mathrm{~mol}^{-1}$, indicating MEK and TOL are physically adsorbed

410 onto SBAC and KBAC.

411 The $\Delta H s$ of MEK and TOL on SBAC are nearly constant $\left(\approx 45.47\right.$ and $45.52 \mathrm{~kJ} \mathrm{~mol}^{-}$

$412^{1}$, respectively) and are independent of temperature within the range of surface loading.

413 This implies a relatively energetic homogeneity of the adsorbent surface [33]. However,

414 as observed in Figure $8 \mathrm{c}$, the $\Delta H s$ of MEK on $\mathrm{KBAC}$ at $30^{\circ} \mathrm{C}$ is relatively lower. One

415 explanation is the surface heterogeneity of adsorbent [34], but this also may be

416 attributed to an experimental error in measuring the adsorption isotherm. It should be

417 noted in Figure 8d that $\Delta H s$ for TOL adsorption on KBAC increased drastically at a

418 higher surface loading, which reflected stronger dependence upon surface loading.

419 Such results are consistent with those of Chen et al. [17] and can be explained by the

420 follows: (1) the surfaces of KBAC are energetically heterogeneous towards adsorption

421 of TOL [35], (2) the stronger lateral interactions occurred between the adsorbed

422 molecules at a higher surface coverage [36], or (3) as surface loading increases, more

423 vital interaction between TOL (weak polarity) and the nonpolar adsorbent resulting in

424 high heats of adsorption. 


\subsubsection{Microwave regeneration}

The desorption efficiencies for BACs were evaluated for different power outputs

$427(400,600,800$, and $1000 \mathrm{~W})$ and durations (4, 8, and $12 \mathrm{~min})$ based on the gravimetric and integration methods with a constant nitrogen gas flow rate of 2.0 SLPM (Figures 9

429 and 10).

Within 12 min of microwave irradiation, desorption efficiencies based on the

431 gravimetric method reached $110.7 \pm 14.4,104.4 \pm 2.6,90.2 \pm 2.3$, and $85.5 \pm 5.7 \%$ for

432 MEK-SBAC, MEK-KBAC, TOL-SBAC, and TOL-KBAC, respectively. It could be

433 seen that the desorption efficiencies for SBAC were generally higher, probably because

434 the size of SBAC was smaller (spherical diameter of $218.3 \pm 19.3 \mu \mathrm{m}$ and $700.7 \pm 20.3$

$435 \mu \mathrm{m}$ for SBAC and KBAC, respectively), therefore enhanced heat retention (i.e., hot

436 spots formation) and accelerated the desorption of VOCs within the carbon bed. Overall,

437 SBAC demonstrated better desorption performance and higher energy utilization

438 efficiency in the desorption process.

In addition, the desorption efficiencies of MEK appeared to be greater than that of

440 TOL on both SBAC and KBAC. It could be attributed to the lower boiling point of

441 MEK, the difference in dielectric permittivity, or the polarizability between the two 
444 the gravimetric method were consistently higher than that of the integration method.

445 For MEK-SBAC, the effluent gas analysis results showed $\mathrm{CO}$ plus $\mathrm{CO}_{2}$ weighed

446 approximately $85.52 \mu \mathrm{g}$ as $\mathrm{C}$, causing an average of $28.01 \%$ of efficiency difference.

447 There was no other apparent gas outflow. Thus, the results supported the inference that

448 MEK was decomposed into inorganic compounds during the heating process [38].

449 However, $\mathrm{CO}$ and $\mathrm{CO}_{2}$ released from MEK-KBAC were hardly observed. Instead, a

450 significant $\mathrm{SO}_{2}$ emission $(25.04 \mu \mathrm{g}$ as $\mathrm{S})$ might be generated from removing sulfur at

451 higher temperatures was considered the main reason for the overestimation of

452 desorption efficiencies based on the gravimetric method, in an average of $22.37 \%$ of

453 efficiency difference.

454 On the other hand, for TOL on BACs, the efficiency evaluated by desorption

455 concentration was only slightly lower than that by weight change $(-4.31 \%$ and $-4.48 \%$

456 on average for TOL-SBAC and TOL-KBAC, respectively). A possible explanation was

457 that TOL reacting with oxygen-containing groups on the surface of carbon and

458 transformed into inorganic compounds (i.e., $\mathrm{CO}$ or $\mathrm{CO}_{2}$ ), which could not be detected 
459 by a THC detector [39]. This was also reflected in the results of elemental analysis

460 (Table 1), in which the percentage of oxygen in the BACs slightly decreased after

461 adsorption and regeneration.

462 According to the gas analysis results, for TOL-SBAC, $\mathrm{CO}$ plus $\mathrm{CO}_{2}$ was about

$46357.02 \mu \mathrm{g}$ as C (causing about $6.19 \%$ of efficiency difference). Nevertheless, for TOL-

$464 \mathrm{KBAC}$, the amount of releasing $\mathrm{CO}$ plus $\mathrm{CO}_{2}$ was only $1.37 \mu \mathrm{g}$ as $\mathrm{C}$ (causing only

465 about $0.22 \%$ of difference) and accompanied by $3.08 \mu \mathrm{g}$ as $\mathrm{S}$ of $\mathrm{SO}_{2}$ release. In brief,

466 the results showed that the efficiency differences of TOL-SBAC were possibly

467 associated with the reaction of TOL on the carbon surface. However, the efficiency

468 difference of TOL-KBAC might be due, in large part, to the release of impurities such

469 as sulfur and moisture, accordingly overestimated the efficiency obtained from weight

470 change.

471 3.2.4. Evaluation on reusability of BACs via cyclic adsorption/regeneration experiments

BAC samples were subjected to 8-cycle of adsorption/regeneration to examine

474 their reusability. In addition, the adsorption capacity in each cycle was evaluated by the

475 gravimetric method. 
Figure 11 shows the adsorption capacity/efficiency of BAC samples. The

477 adsorption capacity of KBAC slightly fluctuated in the range of 114.2-115.9 and

$478 \quad 237.2-306.4 \mathrm{mg} \mathrm{g}^{-1}$ for MEK and TOL, respectively. The slight decrease in adsorption

479 capacity proved good stability, which the maintained porous properties could explain

480 throughout the cycles.

481 The adsorption capacity for MEK-SBAC was generally higher than the initial value

482 after each regeneration cycle. However, according to Table 1 , the $S_{\text {total }}$ and $V_{\text {total }}$ of

483 MEK-SBAC (800 W-8min) after the 8-cycle of adsorption/regeneration decreased,

484 indicating the improvement of adsorption capability had nothing to do with the pore

485 structures; instead, the more likely explanation rests in the more critical polarity

486 resulted from the growing $\mathrm{H}$ and $\mathrm{O}$ ratio.

In contrast, the adsorption capacity of TOL-SBAC gradually decreased throughout

488 the cycles. As shown in Table 1, the total and microporous surface area and pore volume

489 of TOL-SBAC significantly declined after 8 -cycle $800 \mathrm{~W}$-8min microwave irradiation.

490 It has been proved that coke species grow at higher temperatures and reach molecule

491 sizes larger than pores, the blocking phenomenon becomes severer especially for

492 materials with highly-developed micropore structures such as SBAC in this study. As 
493 a result, TOL being a typical aromatic compound was trapped and prohibited from

494 diffusion within the pore structures during the regeneration process [40]. This could 495 explain the loss in adsorption capacity, or the buildup of heel was not notable in KBAC 496 loaded with TOL throughout the cycles but led to a maximum of $35 \%$ of capacity loss 497 in SBAC. Nevertheless, the overall adsorption capacity of SBAC for TOL still 498 prevailed among the two samples over the 8-cycle of adsorption/regeneration even 499 though a sever decrease in adsorption capacity had occurred.

500 3.2.5. Desorption kinetics of BACs

501 Desorption kinetics analysis involving mass transfer models is of great importance

502 for simulating lab-scale experiments and practical engineering design. In this section,

503 we used batch experiments to determine the external mass transfer constants $\left(k_{l}\right)$ and 504 intraparticle diffusivities $\left(k_{p}\right)$ for both BAC samples loaded with MEK and TOL at 505 different microwave powers $(400,600,800$, and $1000 \mathrm{~W})$, the simulation results are 506 tabulated in Table S5. 
$0.204 \pm 0.021 \mathrm{~min}^{-1}$, respectively. When saturated with TOL, as power outputs

511 increased from 400 to $1000 \mathrm{~W}$, the $k_{l}$ increased from $0.026 \pm 0.007$ to $0.170 \pm 0.009$

$512 \min ^{-1}$.

513

As for MEK-SBAC, the value of $k_{l}$ at 400 to $1000 \mathrm{~W}$ ranged from $0.309 \pm 0.030$

514 to $0.372 \pm 0.027 \mathrm{~min}^{-1}$, which were higher than that of TOL-SBAC in which values

515 were ranging from $0.158 \pm 0.044$ to $0.232 \pm 0.031 \mathrm{~min}^{-1}$. This result could be supported

516 by the aforementioned proposed evidence of stronger interaction between TOL and the

517 nonpolar surface of SBAC or the formation of chemically adsorbed TOL that was hard

518 to remove.

519 The simulation results summarized in Table S5 suggested the rate-limiting step for

520 MEK and TOL desorption would be intraparticle diffusion. In SBAC and KBAC loaded

521 with MEK, there was no much difference in the $k_{f}$ values at various power outputs.

522 However, the $k_{f}$ of TOL-SBAC significantly increased within the range of $18.07 \pm 1.72$

523 to $22.20 \pm 0.98 \mathrm{mg} \mathrm{g}^{-1} \mathrm{~s}^{-1 / 2}$ while that of TOL-KBAC remained relatively low, ranging

524 from $4.30 \pm 1.18$ to $11.33 \pm 0.64 \mathrm{mg} \mathrm{g}^{-1} \mathrm{~s}^{-1 / 2}$ as microwave powers increased from 400

525 to $1000 \mathrm{~W}$. Among each scenario, it is worth noting that the effect of the boundary layer

526 (I) between the bulk phase of desorbed TOL and TOL-SBAC was extremely large, 
527 which could be supported by the explanation of trapping TOL molecules in the

528 micropore structures due to pore blockage by coke species in microporous materials $529 \quad[40]$.

530 4. Conclusions

531 To summarize, self-prepared high-surface-area beaded activated carbon (SBACs)

532 were successfully synthesized using PF resins under optimal conditions of

533 carbonization and physical activation $\left(\mathrm{CO}_{2}\right)$. SBAC possessed the largest total surface

534 area of $2114 \mathrm{~m}^{2} \mathrm{~g}^{-1}$ compared with bamboo-tar-derived BACs and the commercial

535 KBAC. Additionally, the micropore structures in SBACs contributed to over $98 \%$ of

536 the total surface area. The adsorption performance of BACs samples was evaluated by

537 fitting with isotherms, which confirmed physical adsorption dominated the adsorption

538 processes and the amount of the loading adsorbate influenced the adsorption heat.

539 Microwave regeneration was proved to be effective and feasible in regenerating BAC

540 samples within a short period. Cyclic tests verified the regenerability of the exhausted

541 BAC samples and revealed the heel-buildup might occur in the case of SBAC loaded

542 with TOL due to the pore blockage by coke species during the heating process. Kinetics

543 analysis further provided the core parameters of importance to the estimation and

544 designing of either lab-scale or enlarged-engineering scale adsorbent beds. However, a 
545 method to track the actual temperature of samples during regeneration should be

546 developed to analyze the heating behavior of the adsorbent thoroughly. Future studies

547 should also consider regenerating adsorbents in-situ to reduce the complexity and

548 increase the accuracy in multi-cycle adsorption/regeneration tests.

\section{Declarations}

\section{$551 \quad$ Availability of data and materials}

552 All data generated or analyzed during this study are included in this published article

553 and its supplementary materials.

\section{Competing interests}

555 The authors declare they have no competing interests.

\section{$556 \quad$ Funding}

557 This work was financially supported by the Ministry of Science and Technology,

558 Taiwan under Grant no. 108-2218-E-002-068-MY3.

\section{Authors' contributions}

560 Conceptualization, H.C.H., C.W., and J.G.D.; methodology, S.Y.H. and H.C.H.;

561 formal analysis, S.Y.H. and S.W.Y.; data curation, S.Y.H. and S.W.Y.; writing- 
original draft preparation, S.Y.H. and H.C.H.; writing—review and editing, S.W.Y. and

563 H.C.H.; visualization, S.Y.H.; funding acquisition, H.C.H., C.W., and J.G.D. All

564 authors read and approved the final manuscript.

\section{Acknowledgements}

566 This work was financially supported by the Ministry of Science and Technology,

567 Taiwan under Grant no. 108-2218-E-002-068-MY3. The opinions expressed in this

568 paper are not necessarily those of the sponsor.

$570 \quad$ References

571 1. Montero-Montoya R, López-Vargas R, Arellano-Aguilar O. Volatile organic

572 compounds in air: Sources, distribution, exposure and associated illnesses in

$573 \quad$ children. Ann. Glob. Health. 2018;84(2):225-38.

574 2. Zhang X, Gao B, Creamer AE, Cao C, Li Y. Adsorption of VOCs onto engineered carbon materials: A review. J. Hazard. Mater. 2017;338:102-23.

3. Han MF, Hu XR, Wang YC, Tong Z, Wang C, Cheng ZW, et al. Comparison of separated and combined photodegradation and biofiltration technology for the 
4. Zhang H, Dai L, Feng Y, Xu Y, Liu Y, Guo G, et al. A resource utilization method for volatile organic compounds emission from the semiconductor industry: Selective catalytic oxidation of isopropanol to acetone over $\mathrm{Au} / \alpha-\mathrm{Fe}_{2} \mathrm{O}_{3}$ nanosheets. Appl. Catal. B. 2020;275:119011.

5. Pi X, Sun F, Gao J, Zhu Y, Wang L, Qu Z, et al. Microwave irradiation induced high-efficiency regeneration for desulfurized activated coke: A comparative study with conventional thermal regeneration. Energy Fuels. 2017;31(9):9693-702.

6. Lv Y, Sun J, Yu G, Wang W, Song Z, Zhao X, et al. Hydrophobic design of adsorbent for VOC removal in humid environment and quick regeneration by microwave. Microporous Mesoporous Mater. 2020;294:109869.

7. Wickramaratne NP, Jaroniec M. Importance of small micropores in $\mathrm{CO}_{2}$ capture by phenolic resin-based activated carbon spheres. J. Mater. Chem. 2013;1(1):112-6.

8. Bansal RC, Goyal M. Activated Carbon Adsorption. CRC Press; 2005.

593

9. Ruthven DM. Fundamentals of adsorption equilibrium and kinetics in microporous solids. Springer, Berlin, Heidelberg; 2006. 
synthesized from nanocellulose for $\mathrm{CO}_{2}$ capture and extremely selective removal of volatile organic compounds. Adv. Sustain. Syst. 2018;2(2):1700147.

598 11. Luo L, Ramirez D, Rood MJ, Grevillot G, Hay KJ, Thurston DL. Adsorption and 599 electrothermal desorption of organic vapors using activated carbon adsorbents with 600 novel morphologies. Carbon. 2006;44(13):2715-23.

601 12. Wang H, Lashaki MJ, Fayaz M, Hashisho Z, Philips JH, Anderson JE, et al. 602 Adsorption and desorption of mixtures of organic vapors on beaded activated 603 carbon. Environ. Sci. Technol. 2012;46(15):8341-50.

604 13. Romero-Anaya AJ, Lillo-Ródenas MA, Linares-Solano A. Activation of a spherical 605 carbon for toluene adsorption at low concentration. Carbon. 2014;77:616-26.

606 14. Zhang J, Zhang W, Zhang H, Pang J, Cao G, Han M, et al. Facile preparation of 607 water soluble phenol formaldehyde resin-derived activated carbon by $\mathrm{Na}_{2} \mathrm{CO}_{3}$ 608 activation for high performance supercapacitors. Mater. Lett. 2017;206:67-70.

609 15. Tripathi NK. Porous carbon spheres: Recent developments and applications. AIMS $610 \quad$ Mater. Sci. 2018;5(5):1016-52.

611 16. Chen YT, Huang YP, Hsi HC. Valorizing waste bamboo tar to novel bead 612 carbonaceous adsorbent for volatile organic compound removal. J. Environ. Eng. 
614 17. Chen YT, Huang YP, Wang C, Deng JG, Hsi HC. Comprehending adsorption of methylethylketone and toluene and microwave regeneration effectiveness for beaded activated carbon derived from recycled waste bamboo tar. J. Air Waste Manag. Assoc. 2020;70(6):616-28.

618

18. Dinh TV, Choi IY, Son YS, Song KY, Sunwoo Y, Kim JC. Volatile organic compounds (VOCs) in surface coating materials: Their compositions and potential as an alternative fuel. J. Environ. Manage. 2016;168:157-64.

19. Zhong Z, Sha Q, Zheng J, Yuan Z, Gao Z, Ou J, et al. Sector-based VOCs emission factors and source profiles for the surface coating industry in the Pearl River Delta region of China. Sci. Total Environ. 2017;583:19-28.

20. Singh KP, Mohan D, Tandon GS, Gupta GSD. Vapor-phase adsorption of hexane and benzene on activated carbon fabric cloth: Equilibria and rate studies. Ind. Eng. Chem. Res. 2002;41(10):2480-6.

21. Fournel L, Mocho P, Brown R, le Cloirec P. Modeling breakthrough curves of volatile organic compounds on activated carbon fibers. Adsorption. 2010;16(3):147-53. 
631 kinetic studies of gas-phase mercury adsorption by raw and bromine modified activated carbon. Fuel Process. Technol. 2015;134:325-32.

633

23. Weber WJ, Morris JC. Kinetics of adsorption on carbon from solution. J. Sanit. Eng.

634 Div. 1963;89(2):31-59.

24. Zhang G, Lei B, Chen S, Xie H, Zhou G. Activated carbon adsorbents with microtoluene removal from air. J. Environ. Chem. Eng. 2021;9(4):105387.

25. Popescu M, Joly JP, Carré J, Danatoiu C. Dynamical adsorption and temperatureprogrammed desorption of VOCs (toluene, butyl acetate and butanol) on activated carbons. Carbon. 2003;41(4):739-48.

26. Niknaddaf S, Atkinson JD, Gholidoust A, Fayaz M, Awad R, Hashisho Z, et al.

642 Influence of purge gas flow and heating rates on volatile organic compound decomposition during regeneration of an activated carbon fiber cloth. Ind. Eng. Chem. Res. 2020;59(8):3521-30. 
28. Do DD. Adsorption analysis: Equilibria and kinetics (with CD-containing computer matlab programs). World Scientific Publishing Company; 1998.

29. Chiang HL, Huang CP, Chiang PC. The adsorption of benzene and 2002;46(1):143-52.

30. Dubinin MM, Stoeckli HF. Homogeneous and heterogeneous micropore structures in carbonaceous adsorbents. J. Colloid Interface Sci. 1980;75(1):34-42. on volatile organic compound adsorption and desorption performance. J. Hazard.

32. Sui H, Liu H, An P, He L, Li X, Cong S. Application of silica gel in removing high concentrations toluene vapor by adsorption and desorption process. J. Taiwan Inst. Mater. 2018;351:117-23.

33. Buss E. Gravimetric measurement of binary gas adsorption equilibria of methanecarbon dioxide mixtures on activated carbon. Gas Sep. Purif. 1995;9(3):189-97. heterogeneous surface. J. Catal. 1972;25(1):131-8. 
35. Park JW, Lee SS, Choi DK, Lee YW, Kim YM. Adsorption equilibria of toluene, dichloromethane, and trichloroethylene onto activated carbon fiber. J. Chem. Eng. Data 2002;47(4):980-3.

36. Chowdhury S, Mishra R, Saha P, Kushwaha P. Adsorption thermodynamics, modified rice husk. Desalination. 2011;265(1):159-68.

37. Kim KJ, Ahn HG. The effect of pore structure of zeolite on the adsorption of VOCs kinetics and isosteric heat of adsorption of malachite green onto chemically

38. Waring CE, Spector M. The mechanism of the thermal decomposition of methyl and their desorption properties by microwave heating. Microporous Mesoporous Mater. 2012;152:78-83.

39. Bhandari PN, Kumar A, Bellmer DD, Huhnke RL. Synthesis and evaluation of biochar-derived catalysts for removal of toluene (model tar) from biomassgenerated producer gas. Renew. Engerg. 2014;66:346-53. 
Table 1 Physical and chemical properties of adsorbent

\begin{tabular}{|c|c|c|c|c|c|c|c|c|c|c|}
\hline \multirow[t]{2}{*}{ Sample } & \multicolumn{5}{|c|}{ Component (w.t.\% on dry basis) } & \multirow[b]{2}{*}{$\begin{array}{c}S_{\text {total }} \\
\left(\mathrm{m}^{2} \mathrm{~g}^{-1}\right)\end{array}$} & \multirow[b]{2}{*}{$\begin{array}{c}S_{\text {micro }} / S_{\text {total }} \\
(\%)\end{array}$} & \multirow[b]{2}{*}{$\begin{array}{c}V_{\text {total }} \\
\left(\mathrm{cm}^{3} \mathrm{~g}^{-1}\right)\end{array}$} & \multirow[b]{2}{*}{$\begin{array}{c}V_{\text {micro }} / V_{\text {total }} \\
(\%)\end{array}$} & \multirow[b]{2}{*}{$\begin{array}{l}d_{\text {avg }} \\
(\mathrm{nm})\end{array}$} \\
\hline & $\mathrm{C}$ & $\mathrm{H}$ & $\mathrm{O}$ & $\mathrm{N}$ & $\mathrm{S}$ & & & & & \\
\hline KBAC & 0.12 & 87.61 & 0.77 & 2.95 & 10.86 & 1210.4 & 93.85 & 0.602 & 88.70 & 3.66 \\
\hline SBAC & 1.08 & 82.66 & 0.09 & 2.86 & 11.52 & 2114.3 & 98.61 & 1.361 & 70.39 & 2.65 \\
\hline $\begin{array}{l}\text { MEK-KBAC } \\
800 \mathrm{~W} 8 \mathrm{~min}\end{array}$ & 0.22 & 80.81 & 0.13 & 4.39 & 13.68 & 1104.2 & 98.16 & 0.535 & 94.95 & 2.82 \\
\hline $\begin{array}{c}\text { MEK-SBAC- } \\
800 \mathrm{~W} 8 \mathrm{~min}\end{array}$ & 1.11 & 85.51 & 0.37 & 4.25 & 14.05 & 1737.9 & 98.33 & 0.785 & 98.22 & 2.66 \\
\hline $\begin{array}{l}\text { TOL-KBAC } \\
800 \mathrm{~W} 8 \mathrm{~min}\end{array}$ & 0.20 & 84.37 & 0.13 & 4.24 & 7.11 & 1115.2 & 96.76 & 0.529 & 91.30 & 3.11 \\
\hline $\begin{array}{l}\text { TOL-SBAC } \\
800 \mathrm{~W} 8 \mathrm{~min}\end{array}$ & 0.95 & 85.42 & 0.00 & 2.63 & 4.47 & 1280.1 & 94.69 & 0.598 & 89.30 & 2.52 \\
\hline
\end{tabular}




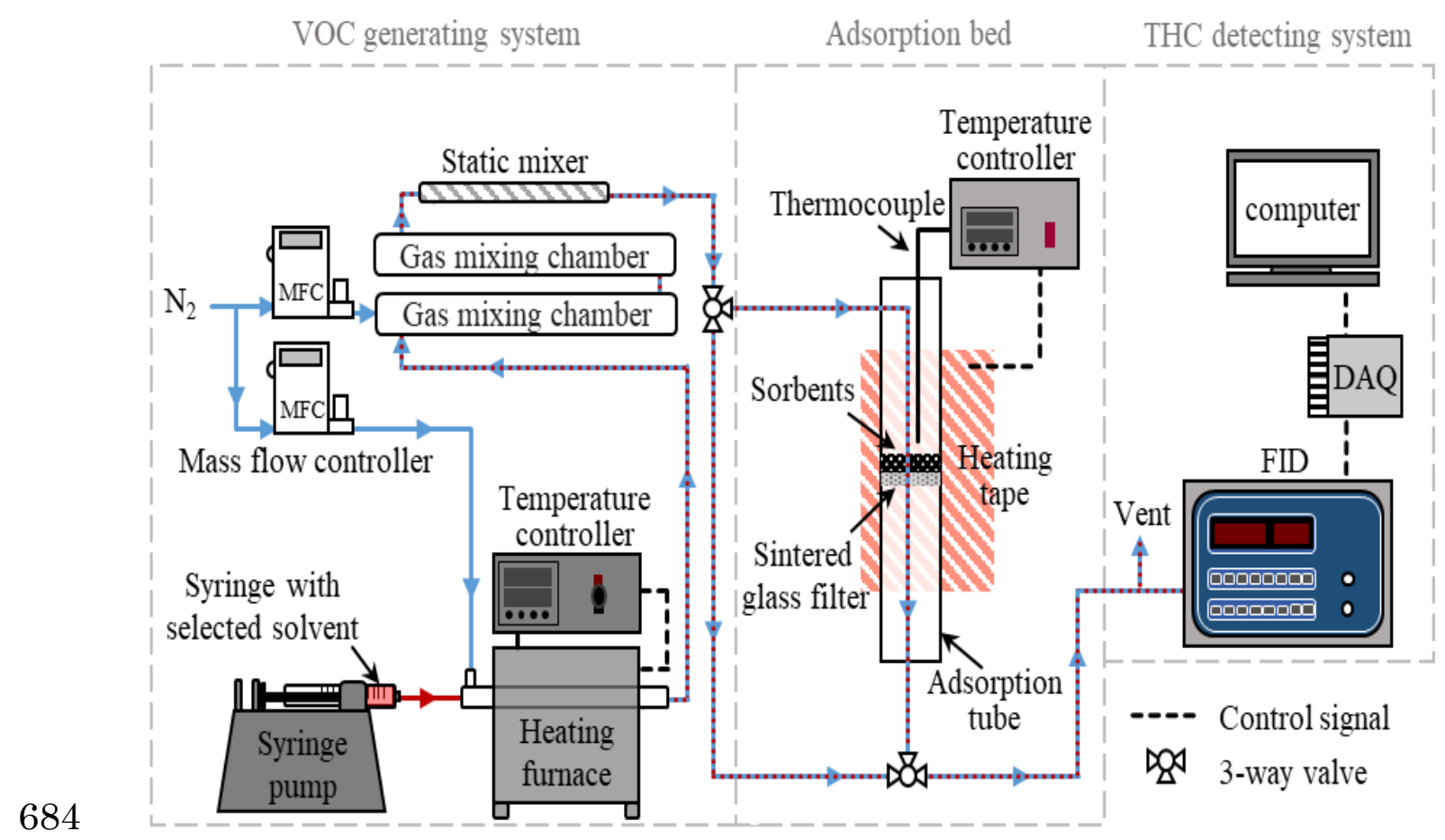

685 Figure 1 Schematic of adsorption testing system setup

686

687

688

689

690

691

692

693

694 

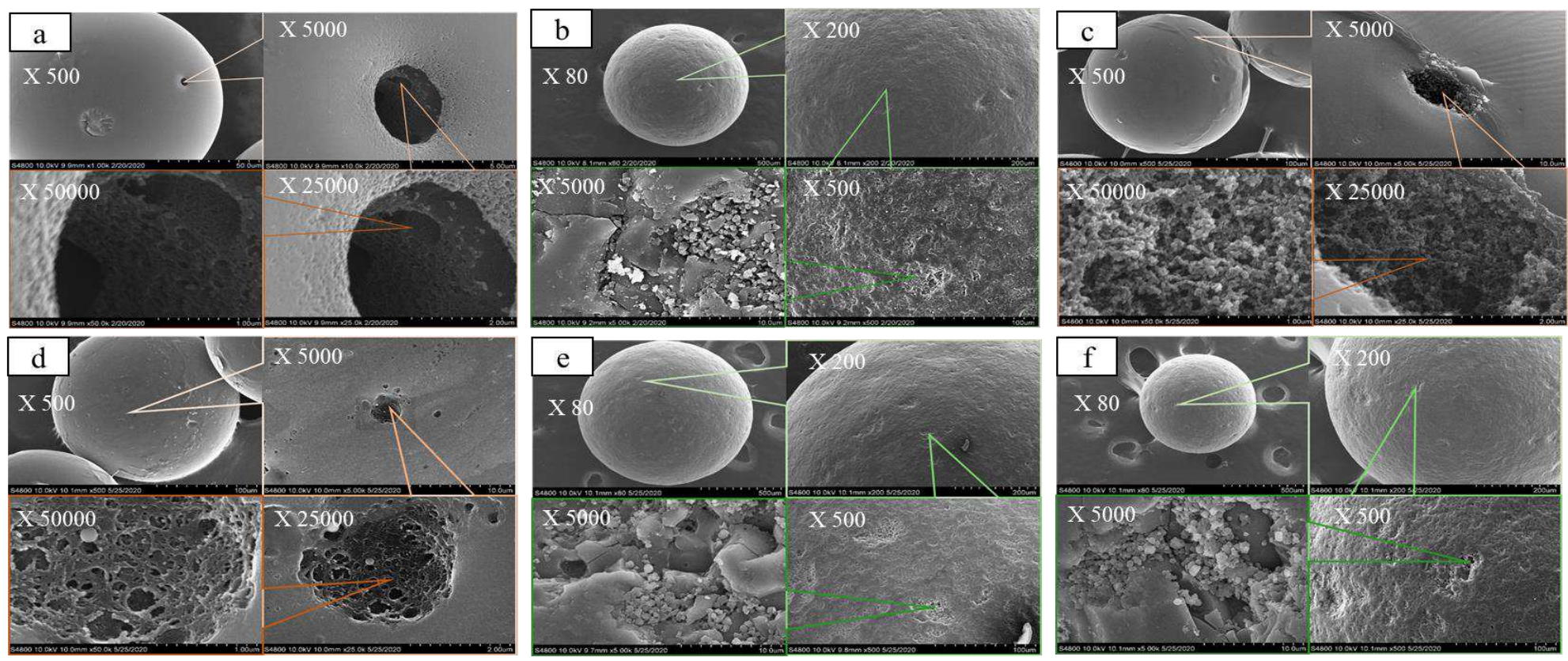

695

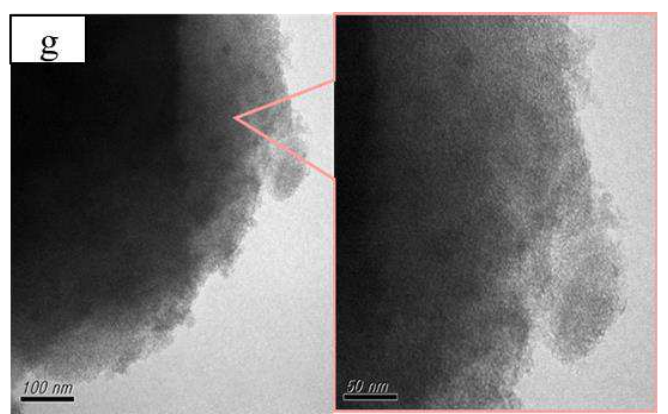

696

Figure 2 SEM micrographs of (a) SBAC, (b) KBAC, (c) MEK-SBAC-800W8min, (d) TOL-SBAC-800W8min, (e) MEK-KBAC-800W8min, (f)

TOL-KBAC-800W8min, and (g) TEM micrograph of SBAC 

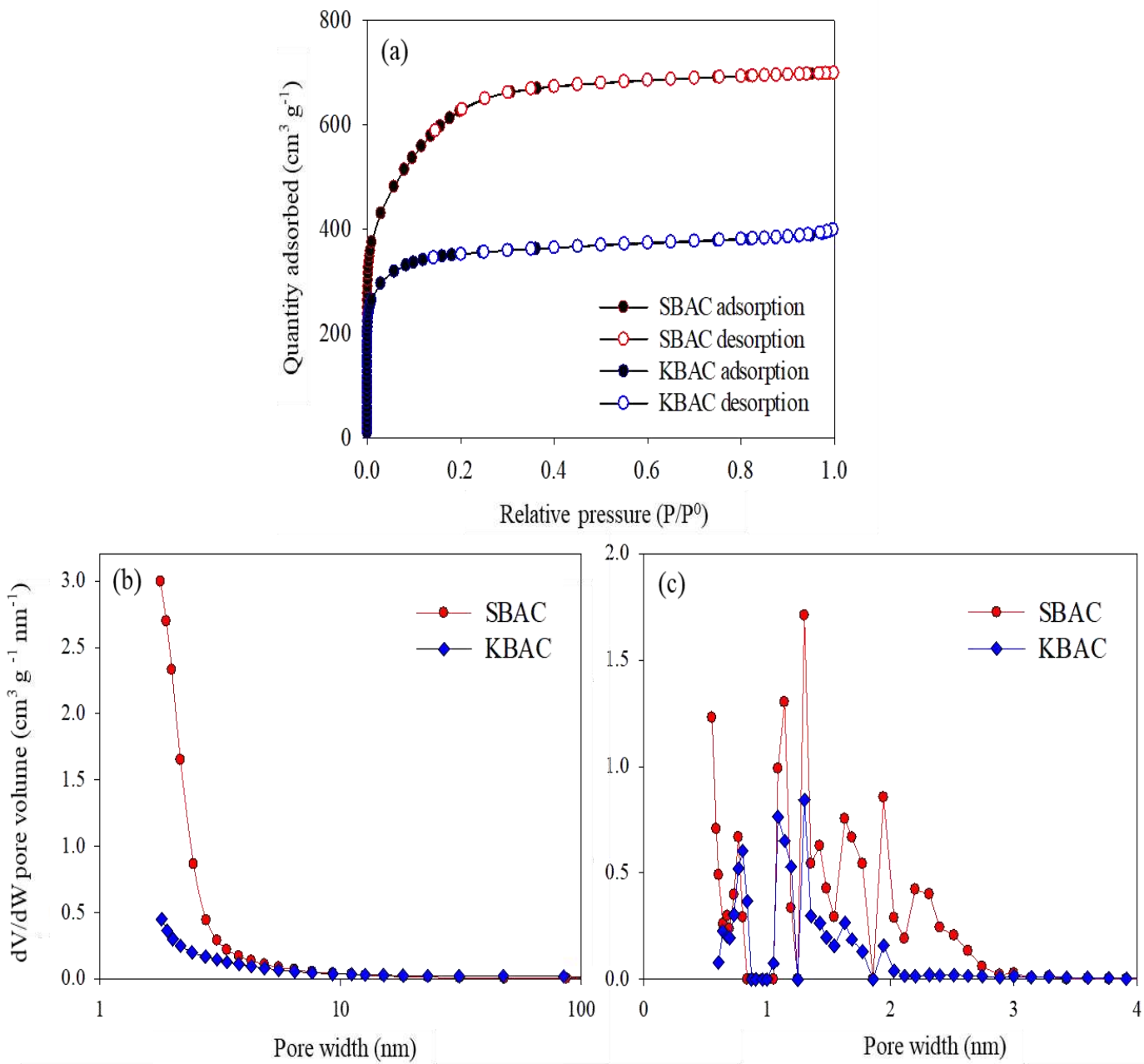

698

Pore width (nm)

699 Figure 3 Pore structure analysis for adsorbents (a) $\mathrm{N}_{2}$ adsorption-desorption isotherms 700 and pore size distribution within (b) mesoporous, macroporous, and (c) microporous 701 regime. 

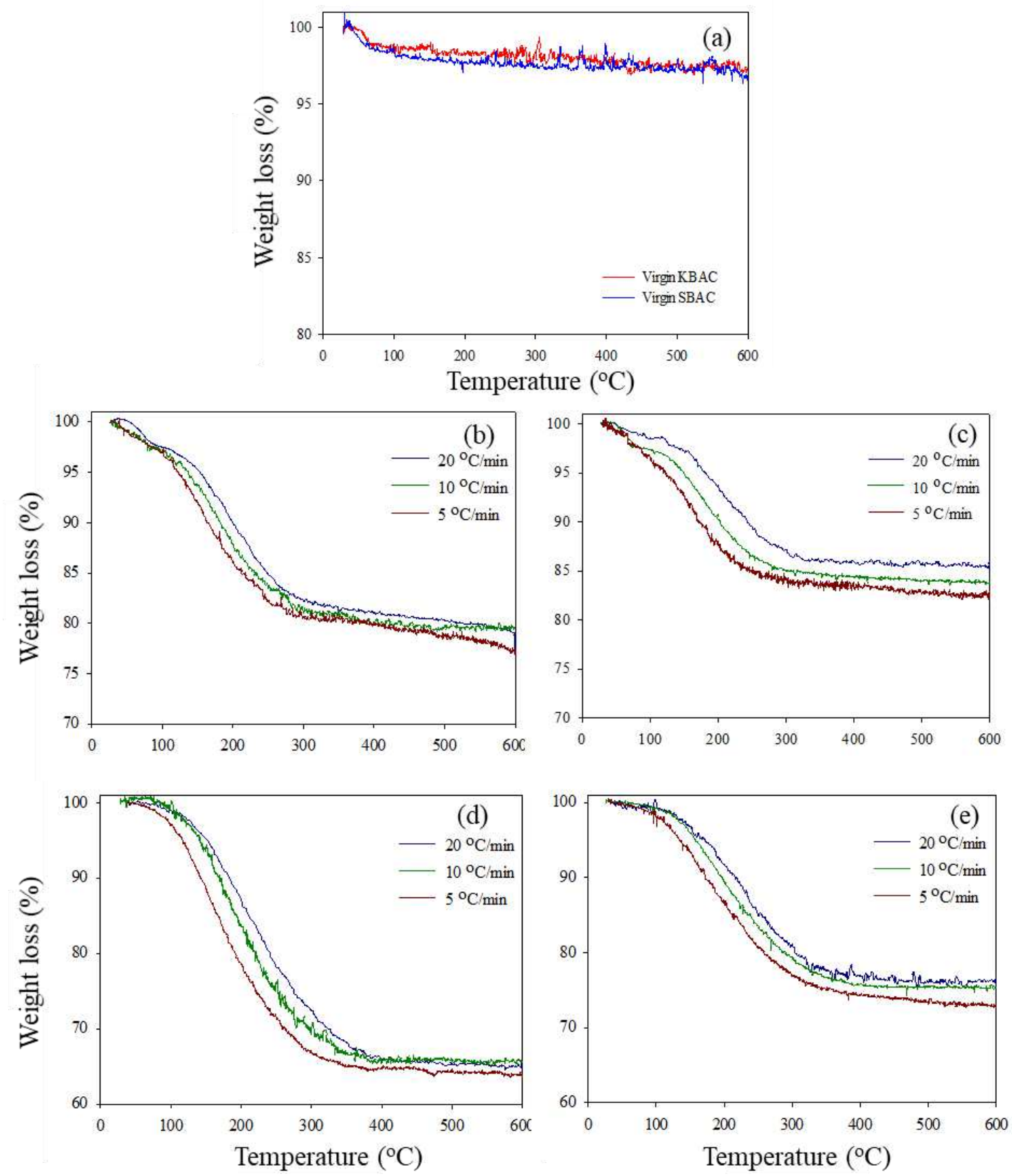

709 Figure 4 TGA curves at heating rates of 5,10 and $20^{\circ} \mathrm{C} \mathrm{min}^{-1}$ for (a) virgin BACs, (b)

710 MEK-SBAC, (c) MEK-KBAC, (d) TOL-SBAC, and (e) TOL-KBAC 

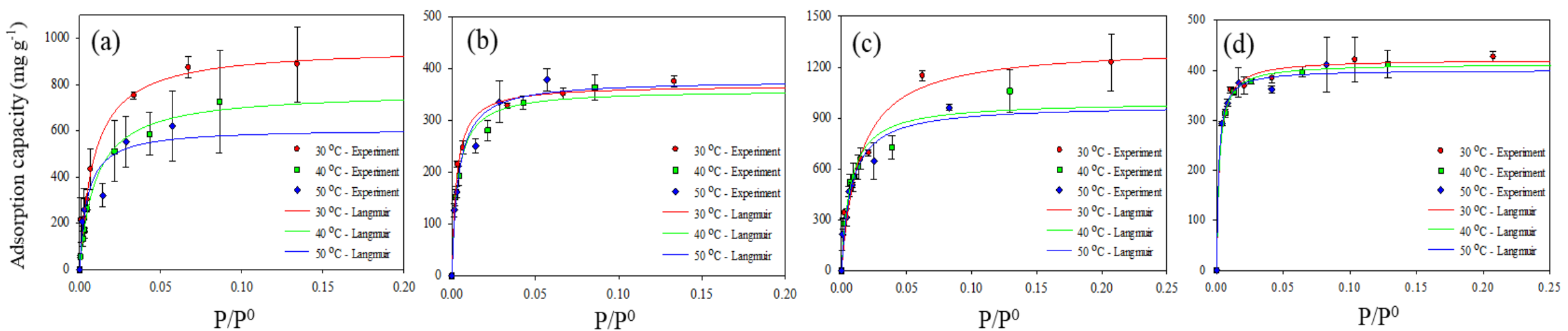

714

715 Figure 5 Experimental and Langmuir modeled adsorption isotherms for MEK on (a) SBAC, (b) KBAC; TOL on (c) SBAC, (d) KBAC by 716 gravimetric method

717

718

719

720 

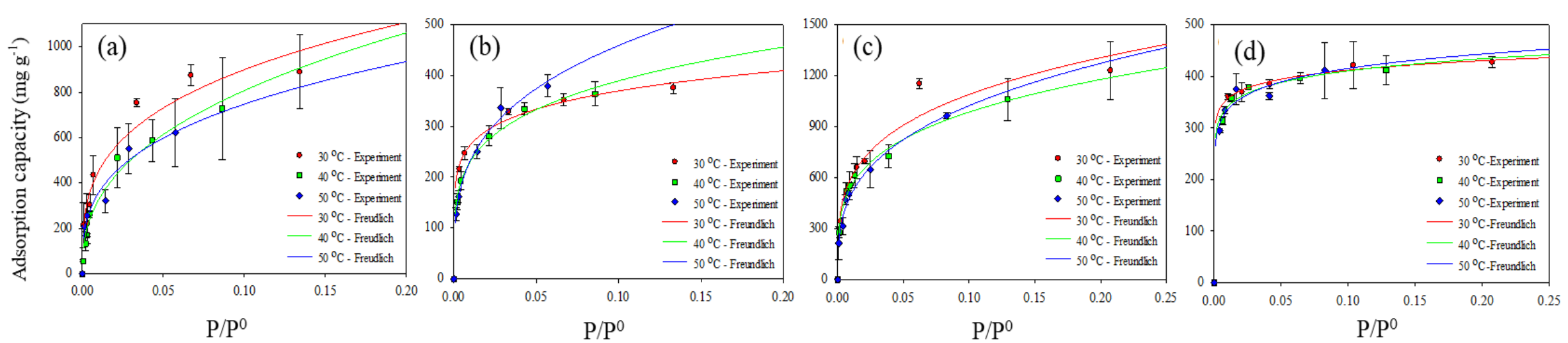

Figure 6 Experimental and Freundlich modeled adsorption isotherms for MEK on (a) SBAC, (b) KBAC; TOL on (c) SBAC, (d) KBAC by 724 gravimetric method 

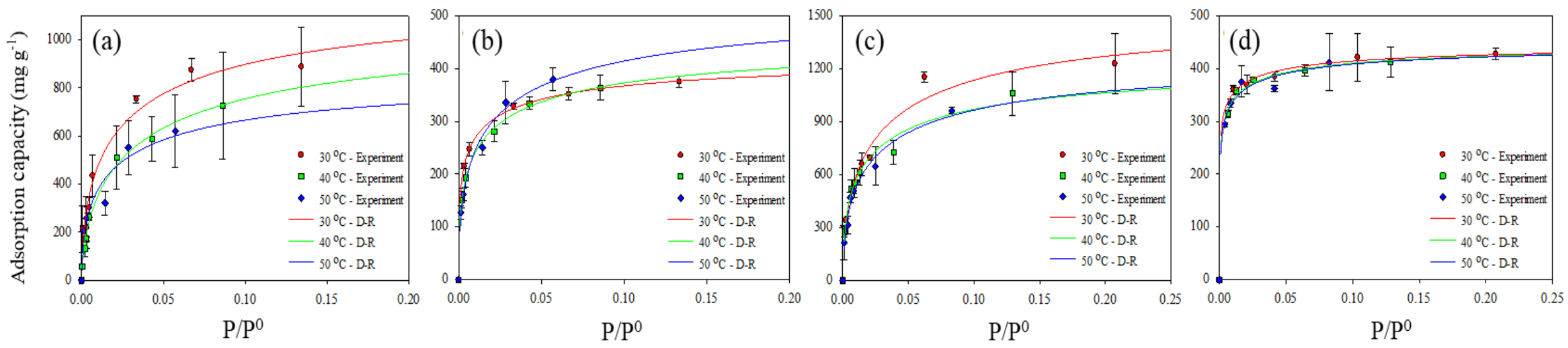

730

Figure 7 Experimental and D-R modeled adsorption isotherms for MEK on (a) SBAC, (b) KBAC; TOL on (c) SBAC, (d) KBAC by gravimetric 732 method 

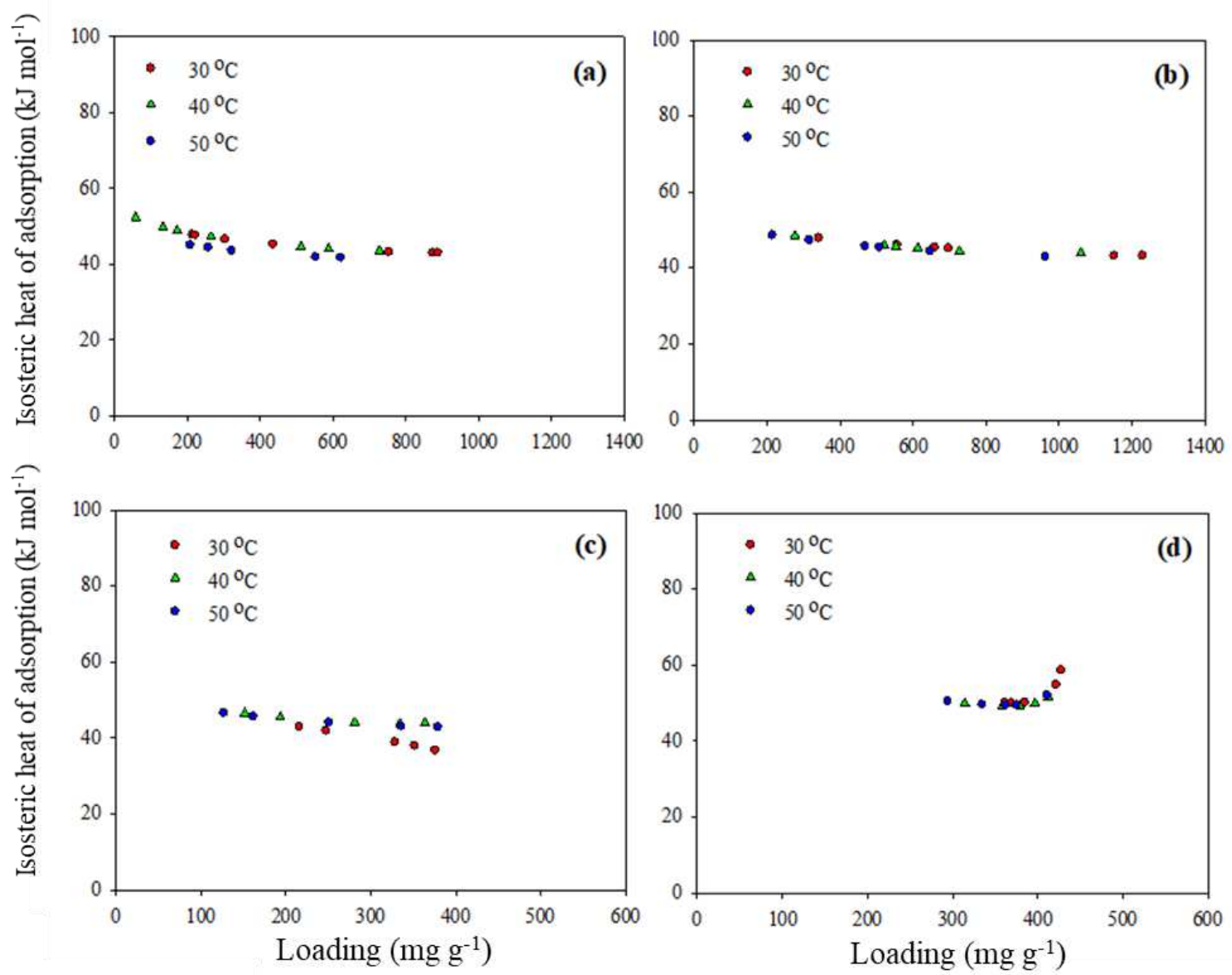

739 Figure 8 Isosteric heat of (a) MEK and (b) TOL adsorption on SBAC; (c) MEK and (d)

740 TOL adsorption on KBAC

741

742

743

744

745

746 



Figure 9 Desorption efficiency evaluated by gravimetric method for (a) MEK-SBAC

750 (b) MEK-KBAC, (c) TOL-SBAC, and (d) TOL-KBAC

751

752

753

754

755

756

757 

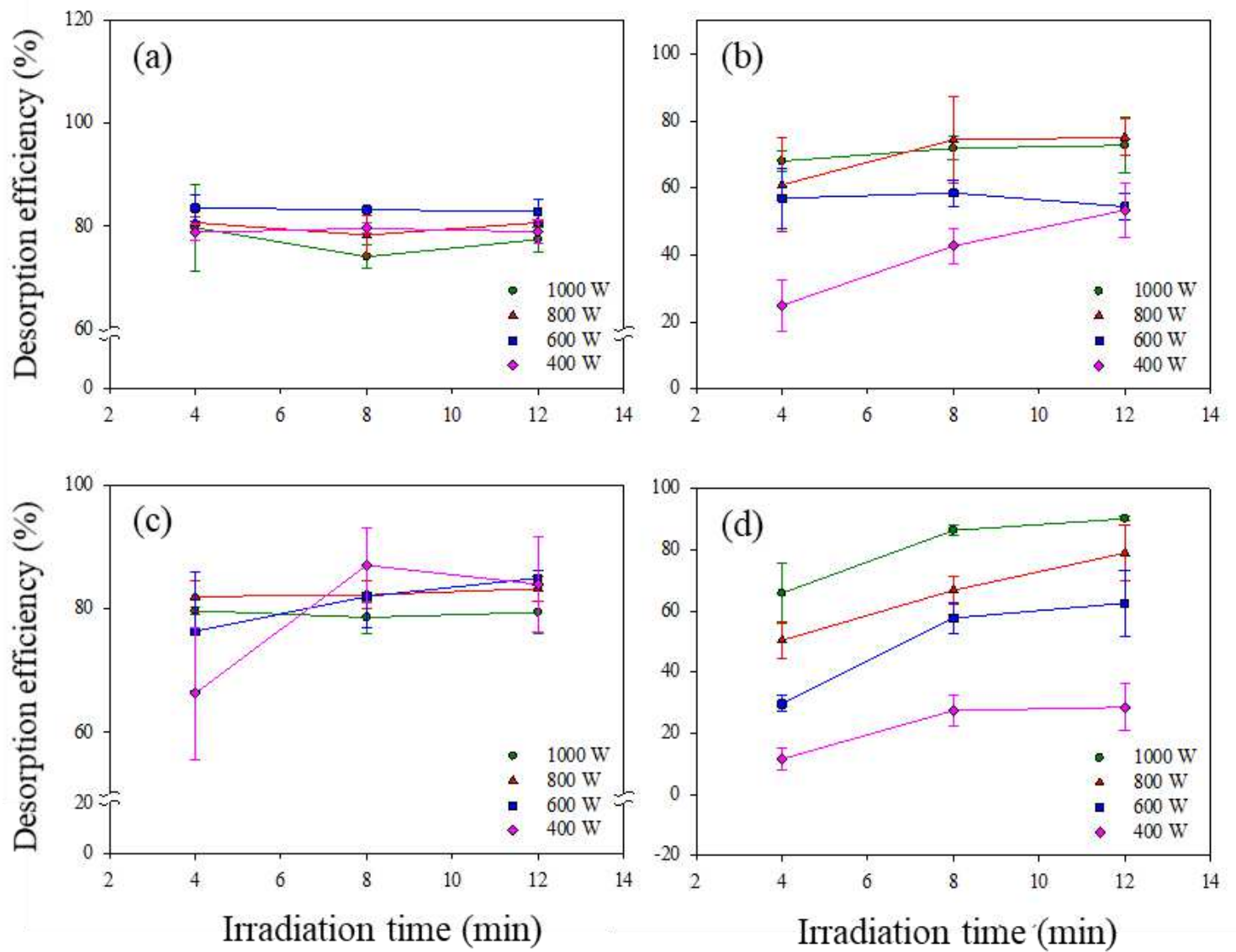

759

Figure 10 Desorption efficiency evaluated by integration method for (a) MEK-SBAC

761 (b) MEK-KBAC, (c) TOL-SBAC, and (d) TOL-KBAC

762

763

764

765

766

767 



Figure 11 Variation in adsorption capacity of (a) MEK-SBAC, (b) MEK-KBAC, (c) 


\section{Supplementary Files}

This is a list of supplementary files associated with this preprint. Click to download.

- SER74SupplementaryMaterials.docx 